\title{
Review of the environmental prenatal exposome and its relationship to maternal and fetal health
}

\author{
Julia E. Rager, ${ }^{\mathrm{a}, \mathrm{b}, \mathrm{c}, *}$, Jacqueline Bangma ${ }^{\mathrm{a}}$, Celeste Carberry ${ }^{\mathrm{a}}$, Alex Chao ${ }^{\mathrm{e}}$, Jarod Grossman ${ }^{\mathrm{f}}$, \\ Kun Lu ${ }^{\mathrm{a}, \mathrm{c}}$, Tracy A. Manuck ${ }^{\mathrm{b}, \mathrm{g}}$, Jon R. Sobus ${ }^{\mathrm{d}}$, John Szilagyi ${ }^{\mathrm{a}}$, Rebecca C. Fry ${ }^{\mathrm{a}, \mathrm{b}, \mathrm{c}}$ \\ ${ }^{a}$ Department of Environmental Sciences and Engineering, Gillings School of Global Public Health, The University of North Carolina at Chapel Hill, Chapel Hill, NC, USA \\ ${ }^{\mathrm{b}}$ The Institute for Environmental Health Solutions, Gillings School of Global Public Health, The University of North Carolina at Chapel Hill, Chapel Hill, NC, USA \\ ${ }^{c}$ Curriculum in Toxicology, The University of North Carolina at Chapel Hill, Chapel Hill, NC, USA \\ ${ }^{\mathrm{d}}$ U.S. Environmental Protection Agency, Office of Research and Development, National Exposure Research Laboratory, Research Triangle Park, NC, USA \\ e Oak Ridge Institute for Science and Education (ORISE) Participant, Research Triangle Park, NC, USA \\ ${ }^{\mathrm{f}}$ Agilent Technologies, Santa Clara, CA, USA \\ ${ }^{\mathrm{g}}$ Department of Obstetrics and Gynecology, Division of Maternal Fetal Medicine, The University of North Carolina at Chapel Hill, Chapel Hill, NC, USA
}

\section{A R T I C L E I N F O}

Keywords:

Exposome

Environment

Fetus

Pregnancy

Developmental toxicity

\begin{abstract}
A B S T R A C T
Environmental chemicals comprise a major portion of the human exposome, with some shown to impact the health of susceptible populations, including pregnant women and developing fetuses. The placenta and cord blood serve as important biological windows into the maternal and fetal environments. In this article we review how environmental chemicals (defined here to include man-made chemicals [e.g., flame retardants, pesticides/ herbicides, per- and polyfluoroalkyl substances], toxins, metals, and other xenobiotic compounds) contribute to the prenatal exposome and highlight future directions to advance this research field. Our findings from a survey of recent literature indicate the need to better understand the breadth of environmental chemicals that reach the placenta and cord blood, as well as the linkages between prenatal exposures, mechanisms of toxicity, and subsequent health outcomes. Research efforts tailored towards addressing these needs will provide a more comprehensive understanding of how environmental chemicals impact maternal and fetal health.
\end{abstract}

\section{Introduction}

\subsection{Introduction to the exposome}

The concept of the "exposome" was introduced in 2005 as "encompass[ing] life-course environmental exposures (including lifestyle factors), from the prenatal period onwards" [1]. This initial definition has since been expanded upon to include three categories: (i) the general external exposome (e.g., lifestyle and socioeconomic factors), (ii) the specific external exposome (e.g., environmental exposures, infectious agents, and therapeutics), and (iii) the internal exposome (e.g., metabolism, circulating hormones, gut microflora, inflammation, and oxidative stress) [2,3]. In short, the exposome is currently a broad term reflecting any non-genetic factor that may play a role in the development of disease.

Evaluating environmental chemicals as part of the human exposome is of high interest, as environmental factors are known to significantly contribute to the global burden of disease [2,4]. At the same time, the majority of chemicals in the environment remain understudied and lack data in relation to both exposures and associated toxicological/health outcomes [5,6]. Methods are currently being expanded upon to evaluate broader chemical domains at increasingly higher rates of throughput [7]. Some recent exposome-relevant examples include studies that have evaluated chemicals in the environment, such as

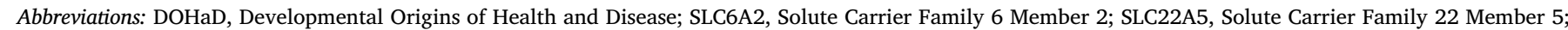

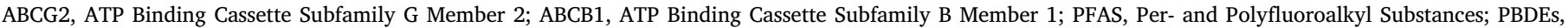

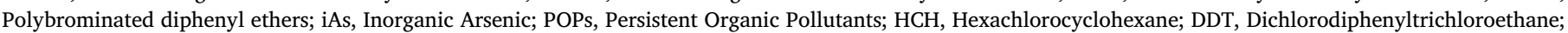

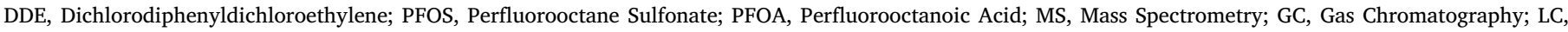

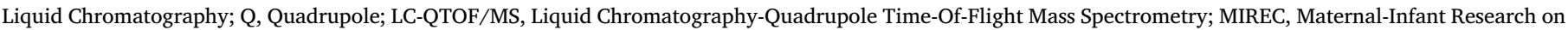

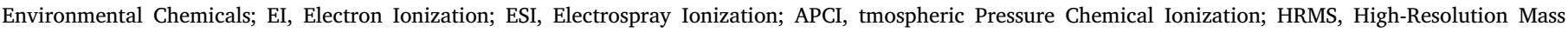
Spectrometry

* Corresponding author at: 135 Dauer Drive, CB 7431, Chapel Hill, NC, 27599, USA.

E-mail address: jrager@unc.edu (J.E. Rager). 
household dust [8-11], drinking water [12-14], and household consumer products [15]. Other notable studies have evaluated exposome measures in biological samples, including circulating blood, teeth, and saliva, and have started linking these measures to health outcomes [16-18].

A critical research topic that remains understudied is the impact of the prenatal environmental exposome on maternal and fetal health outcomes. Addressing this research gap is of high interest as pregnant women and developing fetuses represent populations that are particularly susceptible to potential effects resulting from environmental factors. For example, pregnant women experience shifts in immune cell responses, a hormone-regulated process known to reduce risk of fetal rejection and promote transfer of maternal antibodies to the fetus [19]. With this overall reduction in immune cell responses, pregnant women can exhibit increased risk of certain diseases, including infectious disease [19]. As certain environmental exposures are known to disrupt immune function $[20,21]$, these effects may become exacerbated in pregnant women [22,23]. Within the embryonic environment, rapid cell turnover and tissue growth can cause harmful effects to occur in the developing fetus resulting from certain chemical exposures at lower concentrations than those required to elicit effects in adults [24,25]. These disruptions can also influence health outcomes later in life, a concept also known as the Developmental Origins of Health and Disease (DOHaD) [26]. It is therefore of utmost importance to evaluate the composition and resulting impact of prenatal environmental exposures.

\subsection{The prenatal exposure space and chemical transport}

On a daily basis, pregnant women may be exposed to a vast number of environmental chemicals via ingestion, inhalation, or dermal absorption. Tissue partitioning and excretion rates, which determine how and where these chemicals travel through the maternal body, are influenced by physiochemical properties of chemicals as well as maternal and fetal-specific influences. Important chemical properties that play roles in tissue partitioning and/or excretion include charge [27], lipophilicity [28], protein binding affinity [29], solubility [30], and size/ length [31]. Maternal and fetal-specific influences include metabolic capabilities [32], as well as parameters that commonly change throughout pregnancy, including tissue volumes and blood flow rates, among others [33]. Exposures during pregnancy include complex mixtures of environmental chemicals, many of which partition into maternal blood and are able to reach the placental barrier through the maternal circulation system [34] (Fig. 1). These types of exposures contribute to the 'prenatal exposome', which includes the 'maternal exposome' (or exposures to pregnant women) and the 'fetal exposome' (or exposures that reach the developing fetus). Therefore, chemicals that contribute to the prenatal exposome include those that may impact overall pregnancy health or other pregnancy-relevant outcomes, including impacts on the developing fetus.
Of particular relevance to the developing fetus, environmental chemicals in circulating maternal serum can potentially cross the placenta. Similar to maternal tissue partitioning, this translocation is dependent upon properties of the chemical (e.g., charge, lipophilicity, and size) as well as maternal and placental factors such as metabolism and transporter expression [35,36]. As is the case for other biological barriers, small, lipophilic compounds, such as methylmercury, readily cross the placenta and may even accumulate in the fetal space [37]. The placenta is the interface between mother and fetus, and it serves a multitude of functions, including the regulation of nutrient transfer to the fetus and disposal of fetal waste. Therefore, chemicals passing through the placenta must cross several barriers to reach the fetal circulation. These barriers specifically include: (i) the syncytiotrophoblasts, a fused, multicellular layer that lines the chorionic villi, (ii) the interstitial tissue consisting of cytotrophoblasts, fibroblasts, and connective tissue, collectively comprising the inner mass of the villi, and (iii) the fetal endothelial cells that are present within the villi. Because of their capacity for active transport, the specific barrier function of the placenta is largely regulated by syncytiotrophoblasts $[35,36]$.

Chemical translocation across the placenta can be passive, relying solely on chemical gradients, and/or diffusive, actively driven by transport proteins using ATP or ion gradients as chemical energy sources. Syncytiotrophoblasts express a wide range of xenobiotic transporters that control translocation across the placenta [38]. These include both uptake transporters, such as solute carrier family 6 member 2 (SLC6A2) and solute carrier family 22 member 5 (SLC22A5), and efflux transporters such as ATP binding cassette subfamily B member 1 (ABCB1) and G member 2 (ABCG2) [38]. Of importance to regulating chemical influx/efflux, the apical (maternal facing) and basolateral (fetal facing) membranes of syncytiotrophoblasts each contain a unique profile of transporters. For example, ABCB1 and ABCG2 are both localized on the apical surface of syncytiotrophoblasts, and this, combined with their affinity for a wide range of substrates, allows these proteins to serve in a fetoprotective manner. This fetoprotective activity occurs through the prevention of trans-placental transfer of toxicants or active removal of toxicants from fetal circulation [38]. For instance, ABCG2 prevents the fetal accumulation of medications and environmental contaminants, including glyburide, a medication that may be prescribed for the treatment of pre-gestational or gestational diabetes mellitus, and zearalenone, an estrogenic mycotoxin common in cereal crops [39-41]. Despite the high degree of chemical transport regulation across the placenta, many types of chemicals, including pharmaceuticals and various environmental toxicants, readily pass through the placenta from mother to fetus, potentially impacting fetal health.

\subsection{Focus of review: the prenatal exposome}

The current review focuses on the evaluation of environmental chemicals (defined here to include man-made chemicals [e.g., flame
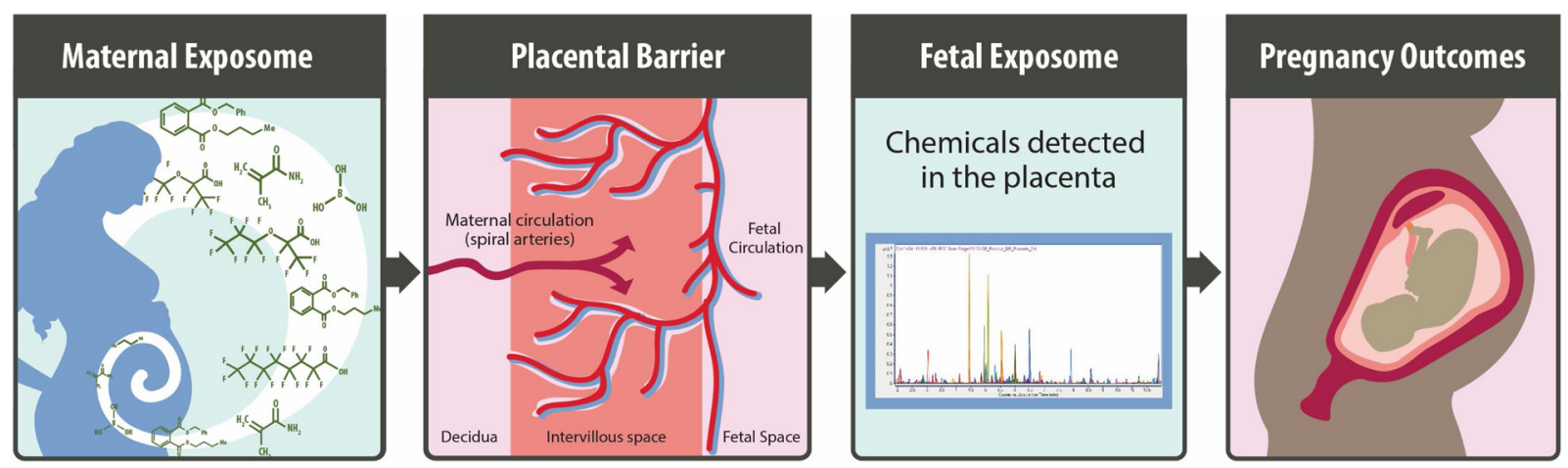

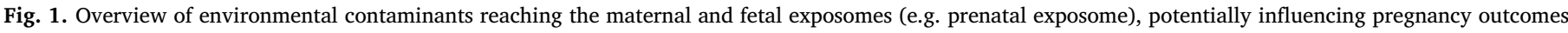
(i.e., maternal and fetal health). 
retardants, pesticides/herbicides, per- and polyfluoroalkyl substances], toxins, metals, and other xenobiotic compounds to which humans come into contact) that reach the placental barrier and travel into human cord blood. The placenta and cord blood were selected for focused review as they represent tissues that are feasible to obtain for research purposes with minimally invasive procedures. Furthermore, these tissues are directly applicable as target tissues involved in pregnancy health outcomes and prenatal developmental toxicity, with focus on the prenatal period, as detailed above. It is important to note that certain previous studies have evaluated the pregnancy exposome through analyses of maternal circulating blood [42,43]. These research approaches contribute valuable information towards understanding relationships between exposure to environmental contaminants and maternal and fetal health outcomes, as noted within a recent review [44]. Here, we focus on studies and future research efforts aimed at the evaluation of environmental chemicals that reach and travel through the placental barrier, as these types of contaminants have the potential to directly impact prenatal development in addition to maternal health.

This review is designed to provide a high-level understanding of the types of research that have been completed aimed at evaluating effects from prenatal exposures to environmental chemicals on maternal and infant health. Included studies represent those that serve as examples from the published literature, selected from PubMed and Google Scholar search queries. Example studies were included if researchers examined environmental chemical exposures during the prenatal period, and either measured chemicals and/or exposure-related effects in the placenta or cord blood. A subset of environmental chemicals was selected as the focus of this review to serve as important case studies based on their known relationships to adverse effects resulting from exposures during the prenatal period. Furthermore, this review comments on critical data gaps and future research directions in the fields of environmental exposure science and pregnancy health outcomes.

\section{Environmental chemicals measured in placenta and cord blood}

Certain classes of environmental chemicals have been shown to travel via maternal circulation and through the placental barrier, impacting the internal environment of pregnant mothers and developing fetuses. Important examples of these chemical classes are provided below and include flame retardants, metals, pesticide and herbicides, per- and polyfluoroalkyl substances (PFAS), as well as naturally occurring toxins. Though other types of environmental chemicals may be present within the prenatal exposome, these specific chemical classes were selected for inclusion in this review as example chemicals with published evidence supporting their presence within human placenta and/or cord blood.

\subsection{Flame retardants}

Flame retardants represent a wide group of chemicals that are commonly used within the indoor environment for the purpose of reducing the potential for materials to ignite [45]. These chemicals are commonly used in building materials, bedding, clothing, and furniture. Exposure to flame retardants can occur dermally as well as via inhalation, for instance through resuspension of chemicals in household dust [46]. Flame retardant exposure has been linked to a variety of health consequences, including endocrine disruption, immune system repression, and cancer $[45,47,48]$. Of particular interest, prenatal exposures to flame retardants have been linked to adverse effects in pregnant mothers and in developing fetuses, including impaired neurologic function, endocrine disruption, and low birth weight for gestational age $[45,48,49]$.

Flame retardants are generally classified by the elements they contain such as bromine, chlorine, phosphorus, nitrogen, boron, or metals. Polybrominated diphenyl ethers (PBDEs) are a class of flame retardants containing bromine that are persistent organic pollutants and have been widely studied in relation to prenatal exposure [46-48,50-52]. Though PBDEs have been banned in US commerce, PBDEs can persist in the environment causing exposures to remain of high relevance. After exposure, PBDEs act as lipophilic compounds and bind to lipoproteins, including those present in circulating plasma. Because of this binding, measurements of PBDEs in the plasma are often normalized to plasma lipoprotein levels [53]. PBDEs can additionally sequester into lipid heavy compartments such as adipose tissue [54] and mother's milk [55].

PBDEs have been evaluated in placental tissue and cord blood $[46,47,50]$, including one study that evaluated cord blood and maternal serum samples across 50 samples and detected PBDEs in every sample, with brominated diphenyl ether 209 accounting for approximately half of all total PBDEs among samples [46]. Several other studies have measured PBDEs in newborn cord blood and placenta and have identified strong correlations between these and maternal exposures measured from circulating serum [47,50,51]. Additionally, studies have shown relationships between PBDE exposure and adverse fetal health outcomes, including low birth weight and impaired neurodevelopment $[48,52]$.

There is a general lack of data surrounding other classes of flame retardants specifically in relation to the prenatal exposome. For example, other classes of brominated flame retardants, such as tetrabromobisphenol A and hexabromocyclododecane, as well as organophosphate flame retardants, are thought to be possible carcinogens and may induce similar adverse health outcomes as PBDEs [45]. There are significantly fewer studies, however, measuring concentrations and toxicity responses of these chemicals in humans [45]. Because of the potential for associated prenatal toxicity, future research efforts aimed at evaluating this understudied chemical space will contribute to the current understanding of pregnancy outcomes associated with flame retardants.

\subsection{Metals}

Various toxic metals, including arsenic, cadmium, chromium, lead, and mercury, have been shown to cross the placenta and accumulate in fetal tissues following prenatal exposure conditions [56-59]. This occurs because metals are relatively stable compounds that can travel to distal target tissues following exposure. For example, inorganic arsenic (iAs) and its metabolites, monomethylated and dimethylated arsenicals, can be present at levels associated with toxicity in target tissues throughout the body $[60,61]$, including the placenta and cord blood $[56,61]$. Cadmium has been detected throughout several target tissues, including maternal blood, placenta, and cord blood, with absorption and distribution shown to be highly dependent upon cadmium binding to metallothionein (MT) metal transporters [62]. Of particular relevance to the prenatal exposome, cadmium concentrations have been identified as increased in placental and fetal tissues from MT knockout mice exposed during late gestation [63]. A number of studies have detected and quantified the concentrations of toxic metals that reach the placenta and/or cord blood as a result of exposure during pregnancy, including those that have identified potential exposure biomarkers and related health outcomes.

As an example study that has investigated iAs throughout several tissues from pregnant women, researchers evaluating a birth cohort in New Hampshire measured iAs concentrations within human placenta samples and related these measures to iAs concentrations in maternal urine, and in maternal and newborn toenail samples [56]. Placental concentrations ranged from below detection limits to $18.35 \mathrm{ng} / \mathrm{g}$ and were positively correlated with iAs concentrations in newborn and maternal urine and toenails [56]. Cadmium has also been measured in placenta and newborn cord blood as reported by a study conducted in Croatia among smoking and non-smoking pregnant mothers [57]. The concentrations of cadmium were elevated in placenta and cord blood samples among mothers who smoked during pregnancy and ranged 
from 8.42 to $15.5 \mathrm{ng} / \mathrm{g}$ in the placenta and $0.025-0.054 \mathrm{ng} / \mathrm{mL}$ in the cord blood [57]. Mercury is another well-researched metal that has been evaluated in relation to prenatal environmental exposures and specifically measured in placenta and cord blood samples $[58,59]$. For instance, a cohort study conducted in Saudi Arabia found that $13 \%$ of $\sim 1500$ cord blood samples had mercury concentrations above the EPA reference dose of $5.8 \mu \mathrm{g} / \mathrm{L}$ [58]. Increasing concentrations of mercury were found to be correlated with seafood consumption and mothers' work status, among other potential factors [58]. These relevant studies measured the ability of various metals to cross the placenta and accumulate in fetal tissues and serve as a basis for future evaluation of associated health outcomes in the context of environmental exposures.

Specific linkages have been made between measures of prenatal exposures to metals and fetal health outcomes, including exposures to arsenic, cadmium, chromium, lead, and mercury [64-67]. For example, the effects of prenatal iAs exposure were evaluated in a pregnancy cohort located in Gómez Palacio, Mexico, and maternal urinary concentrations of iAs and select iAs metabolites showed negative associations with newborn birth weight, newborn length, and gestational age [68]. Further evaluation of newborn cord blood identified molecular signaling patterns that may drive certain mechanisms linking prenatal iAs exposure to fetal health outcomes [20,69]. The potential effects of prenatal exposure to cadmium have also been evaluated, with previous studies finding associations between concentrations in newborn cord blood and decreased newborn birth weight $[57,70]$. These represent select example studies from a pool of research on prenatal exposure to toxic metals that has been reviewed elsewhere [65,65,66,67,71,72]. Clearly there is evidence to support relationships between toxic metals exposures and adverse impacts on maternal and child health outcomes; though there are important aspects of metals research that remain understudied. Critical gaps in research include the impacts of metals as potentially beneficial nutrients versus toxic agents; individual metals that humans are routinely exposed to that still lack data; and metals as mixtures and/or components of complex mixtures within the environment.

\subsection{Pesticides and herbicides}

The increasing usage of pesticides and herbicides has resulted in the accumulation of these chemicals in ecological systems and other environments, causing increases in human exposures and potential related health outcomes. Maternal exposure to herbicides and pesticides classified as persistent organic pollutants (POPs) such as hexachlorocyclohexane (HCH), dichlorodiphenyltrichloroethane (DDT), and dichlorodiphenyldichloroethylene (DDE), among others, may pose a health risk to the developing fetus. Exposures to POPs such as DDT, DDE, or HCH are most likely to occur through consumption of fruits and vegetables, fatty meats, dairy, and fish, especially those imported from countries that allow the use of these chemicals [73]. These chemicals have been shown to reach placenta tissues and cross into cord blood, with potential associations with adverse fetal development and health outcomes among newborns, such as birth weight under $10^{\text {th }}$ percentile for gestational age and decreased head and chest circumference [51,74-76].

Some studies have evaluated levels of pesticides and herbicides in placenta and cord blood. For instance, a birth cohort study conducted in Delhi, India measured and compared the concentrations of the organochlorine pesticides, HCH, DDT, and DDE, in placental tissue and cord blood between small for gestational age newborns and of appropriate size for gestational age newborns [74]. Total HCH concentration in placenta tissues among low birthweight babies averaged $\sim 20 \mathrm{ng} / \mathrm{mL}$; the concentration of DDT averaged $\sim 2 \mathrm{ng} / \mathrm{mL}$; and the concentration of DDE averaged $\sim 4 \mathrm{ng} / \mathrm{mL}$; all representing concentrations higher than those observed in the control newborns [74]. Similarly, a study within a cohort in Canada was able to measure concentrations of certain pesticide and herbicide POPs in cord blood including DDT, DDE, as well as oxychlordane [76]. The concentration of oxychlordane in cord blood was reported to reach up to $50 \mu \mathrm{g} / \mathrm{kg}$ [76]. These studies among others have provided critical evidence surrounding maternal exposures to certain POPs in pesticides and herbicides that are capable of reaching human placenta and cord blood tissues [51,74-76].

Other types of pesticides that are not currently considered POPs have also been evaluated, to an extent, in the context of prenatal exposures, including chlorpyrifos and glyphosate. Chlorpyrifos is an organophosphate pesticide and is presently one of the most widely used herbicides worldwide. Previous studies have associated prenatal exposure to chlorpyrifos to adverse birth outcomes such as decreased birth weight and length, as well as reduced sensory function and neurodevelopment [77-80]. An example study evaluating pesticide exposure among urban minorities in New York City reported concentrations of chlorpyrifos in newborn cord blood averaging $3.7 \mathrm{pg} / \mathrm{g}$. These cord blood concentrations were significantly associated with concentrations in maternal blood, providing further evidence that chlorpyrifos is capable of crossing the placenta [77]. Glyphosate is currently the most used herbicide worldwide, however, fetal risks of exposure remain largely understudied in humans. Few studies have evaluated the ability of glyphosate to reach cross the placental barrier, however, one study in Thailand detected glyphosate in maternal serum and cord blood among farmworkers [81]. The wide use of pesticides and herbicides such as chlorpyrifos and glyphosate and their demonstrated potential to reach the fetus and impact health outcomes calls for further studies investigating these relationships.

\subsection{PFAS}

PFAS are a diverse chemical family of fluorine substituted organic structures that have been used for a wide variety of industrial applications in the United States and worldwide [82]. Only a small portion of PFAS have been evaluated for presence in target tissues relevant to prenatal exposure-induced toxicity, including the perfluoroalkyl acids, perfluorooctane sulfonate (PFOS) and perfluorooctanoic acid (PFOA) [83]. However, over 3000 PFAS are estimated to be in global production [82]. Of timely relevance, a chemical category-based prioritization approach was recently developed by the US EPA to prioritize 75 PFAS for tiered toxicity and toxicokinetic testing based on relevance to human exposure, toxicity, and structural diversity [84]; though this prioritization effort has yet to be carried out with specific focus on the prenatal exposure space. While there is much attention now being focused on PFAS exposure and toxicity, there remains a limited understanding of how PFAS enter and affect the target tissues of relevance to maternal and fetal health. Some initial findings from recent studies are summarized below.

PFAS are known to be proteinophilic, associating with proteins such as albumin, fatty acid binding proteins, and organic anion transporters $[85,86]$. Because circulating blood contains many of these aforementioned proteins, PFAS can be detected at high concentrations in maternal blood, allowing for maternal circulation to carry PFAS to the placental interface where transfer into the fetal exposome occurs throughout pregnancy. The strong affinity of PFAS for maternal blood allows these substances to travel to the placenta and into cord blood circulation as is indicated by high correlations between maternal serum and cord blood serum $[87,88]$. Literature suggests transporters such as the breast cancer resistance protein (BCRP) can play a role in transfer of PFAS across the placental barrier, but overall very little is known concerning the mechanism of PFAS transfer from maternal circulation to fetal circulation [89]. Current data highlight that PFAS with linear structures are usually observed in biological fluids at higher concentrations in comparison to their matching branched isomers [90] and have been identified at higher concentrations in fetal serum relative to maternal serum [91]. This trend may reflect differences in efficiencies between compounds crossing the placenta [92], making PFAS uniquely structured to potentially accumulate in target tissues relevant to the 
fetal exposome. In addition, mothers with gestational diabetes have shown higher transfer efficiencies to cord serum for several PFAS compared to mothers without gestational diabetes [93]. PFAS concentrations have even been shown to increase in the fetal compartment throughout gestation [94], supporting the need for research to better understand potential implications of exposure on fetal health.

A variety of health-related endpoints have been evaluated in relation to PFAS accumulation in human cord blood and placenta with mixed results. For example, studies evaluating prenatal PFAS exposure in pregnancy cohorts in Canada have identified both significant [95] and non-significant [83] associations between PFAS concentrations in cord blood and infant birth weight. Potential alterations in hormonerelated signaling have also been evaluated in a few studies. For example, researchers evaluating a Japanese pregnancy cohort, containing 189 infant-mother pairs, identified associations between cord blood concentrations of PFAS and altered levels of cord blood hormones including estradiol, progesterone, and prolactin, and testosterone [96]. Studies carried out in Taiwan also identified significant relationships between PFAS and a number of endpoints in cord blood including thyroxine, thyroid stimulating hormone, and possible disruption in infant IgE levels [97,98].

Later-in-life outcomes have been evaluated in relation to PFAS to a limited extent and with mixed results. For instance, the study in Taiwan additionally investigated potential associations between cord blood PFAS and neurodevelopment at two years of age and identified decreased gross motor function associated with PFOS [99]. A recent systematic review also found associations between prenatal or early-life PFAS exposure and a range of outcomes including dyslipidemia, immunity (e.g., asthma and vaccine response), renal function, and age at menarche [100]. Other PFAS studies, though, found no associations between cord blood PFAS concentrations and a number of outcomes including attention deficit hyperactivity disorder [101], congenital cryptorchidism [102], and altered endocrine function assessed through circulating thyroid hormone levels [103]. Clearly, further research is needed to better understand prenatal PFAS exposure and its potential impacts on fetal growth and childhood development.

\subsection{Toxins}

Naturally occurring toxins in the environment can be a significant concern, as exposure to these chemicals can induce a variety of adverse health outcomes, inducing developmental toxicity resulting from exposures in utero [104-108]. Compared to the synthetic chemicals and metals previously discussed, studies on the presence of naturally occurring toxins in the prenatal exposome are relatively limited. This may be due to the severity of reactions to these exposures during pregnancy or a lack of understanding of the toxicity of toxins at low, chronic exposure levels. For example, ochratoxin A, a carcinogenic and neurotoxic food contaminant produced by Aspergillus and Penicillium, has been detected in human cord blood samples [109,110]. An example study carried out in Piacenza, Italy detected ochratoxin A in almost all cord blood samples (129 out of 130) evaluated [109]. The concentration of ochratoxin A was also significantly correlated with the participants' intake of pork meat, soft drinks, and red wine.

Aflatoxins, a family of potent liver carcinogens also produced by Aspergillus, have also been assessed in pregnancy cohorts from multiple studies carried out in African countries. Fetal exposure to naturally occurring toxins is of particular interest for developing countries because of the challenges in food storage, both for human and livestock consumption, and the lack of testing and controls for these compounds. In terms of prevalence, aflatoxins $\mathrm{M} 1, \mathrm{M} 2, \mathrm{~B} 1$, and $\mathrm{B} 2$ were detected in $12 \%$ of cord blood samples analyzed in a cohort study conducted in Nigeria [71]. Aflatoxin-albumin adducts were also detected in cord blood samples collected from study participants located in Gambia [72-74]. Potential seasonal effects have been identified, with aflatoxins measured at significantly higher levels in cord blood samples collected in wet vs. dry months in Kenya [76]. Beyond African countries, aflatoxin B1-DNA adducts have been detected in placenta and cord blood samples from a cohort in Taiwan [75]. Such studies indicate the worldwide prevalence of toxins as environmental contaminants that can potentially impact the maternal and fetal exposome.

\section{Current status of the environmental prenatal exposome}

\subsection{Chemical coverage in the prenatal exposome}

There is evidence supporting relationships between prenatal exposure to select environmental chemicals and adverse pregnancy outcomes, as described above. Studies of environmental chemicals in cord blood and placenta samples have generally used targeted analytical approaches, wherein hypotheses related to few specific chemical contaminants are set $a$ priori. These studies have employed mass spectrometry (MS) platforms for compound detection, coupled with gas chromatography (GC) or liquid chromatography (LC) systems for analyte separation. Low-resolution quadrupole (Q) mass analyzers (single or triple Q) generally provide adequate sensitivity and specificity for unambiguous analyte detection. Yet, in all instances of targeted analysis, chemical standards are needed to confirm the presence of each analyte (e.g., via matching of chromatographic retention time and mass spectrum), and to produce quantitative estimates of chemical concentration in the target tissue. This dependence on chemical standards has limited the number of environmental chemicals that have been characterized in cord blood and placenta samples.

To improve the characterization of chemicals in the maternal and fetal exposomes, recent studies have implemented more global approaches based on "suspect screening" or "non-targeted analysis" methods $[42,43]$. By utilizing sophisticated analytical instrumentation, comprehensive chemical databases, and integrated computational workflows (Fig. 2), these complementary methods offer a means to rapidly examine poorly or never-before-studied compounds in highinterest samples [7,111]. In terms of evaluating the maternal/fetal exposome, studies have, to date, focused on the investigation of environmental chemicals in circulating maternal serum. As an important example, a recent study used a suspect screening approach based on liquid chromatography-quadrupole time-of-flight mass spectrometry (LC-QTOF/MS) to screen for environmental organic acids in maternal serum [43]. Researchers identified hundreds of potential environmental organic compounds among 20 samples, spanning phenols, phthalates, perfluorinated compounds, acidic pesticides, and related metabolites, the majority of which are not currently measured in large-scale biomonitoring studies. Targeted analyses confirmed the presence of benzophenone-1, bisphenol S, and monopentyl phthalate within maternal serum [43]. Similar methods were also employed by this research team to evaluate additional maternal serum samples, and an average of 56 suspect environmental organic compounds were reported per sample [42]. Six chemicals were then confirmed using targeted approaches: 2,4-Di-tert-butylphenol, 3,5-Di-tert-butylsalicylic acid, 2,4-Dinitrophenol, 4-Hydroxycoumarin, Pyrocatechol and 2'-Hydroxyacetophenone [42].

These studies represent important examples of how researchers can use global analytical approaches that are less biased than targeted methods to characterize environmental chemicals relevant to prenatal exposures, with a focus on circulating maternal blood. Still, there remains a critical data gap surrounding which chemicals specifically reach the placental barrier and cross into the fetal circulation. As previously discussed, select chemicals have been evaluated in placenta and cord blood tissues using targeted approaches. Notable studies have evaluated hundreds of environmentally relevant chemicals in cord blood and infant meconium samples (for instance through the MaternalInfant Research on Environmental Chemicals [MIREC] Research Platform) $[76,112]$, but these studies have still utilized targeted analytical methods. Future studies could therefore leverage recent 


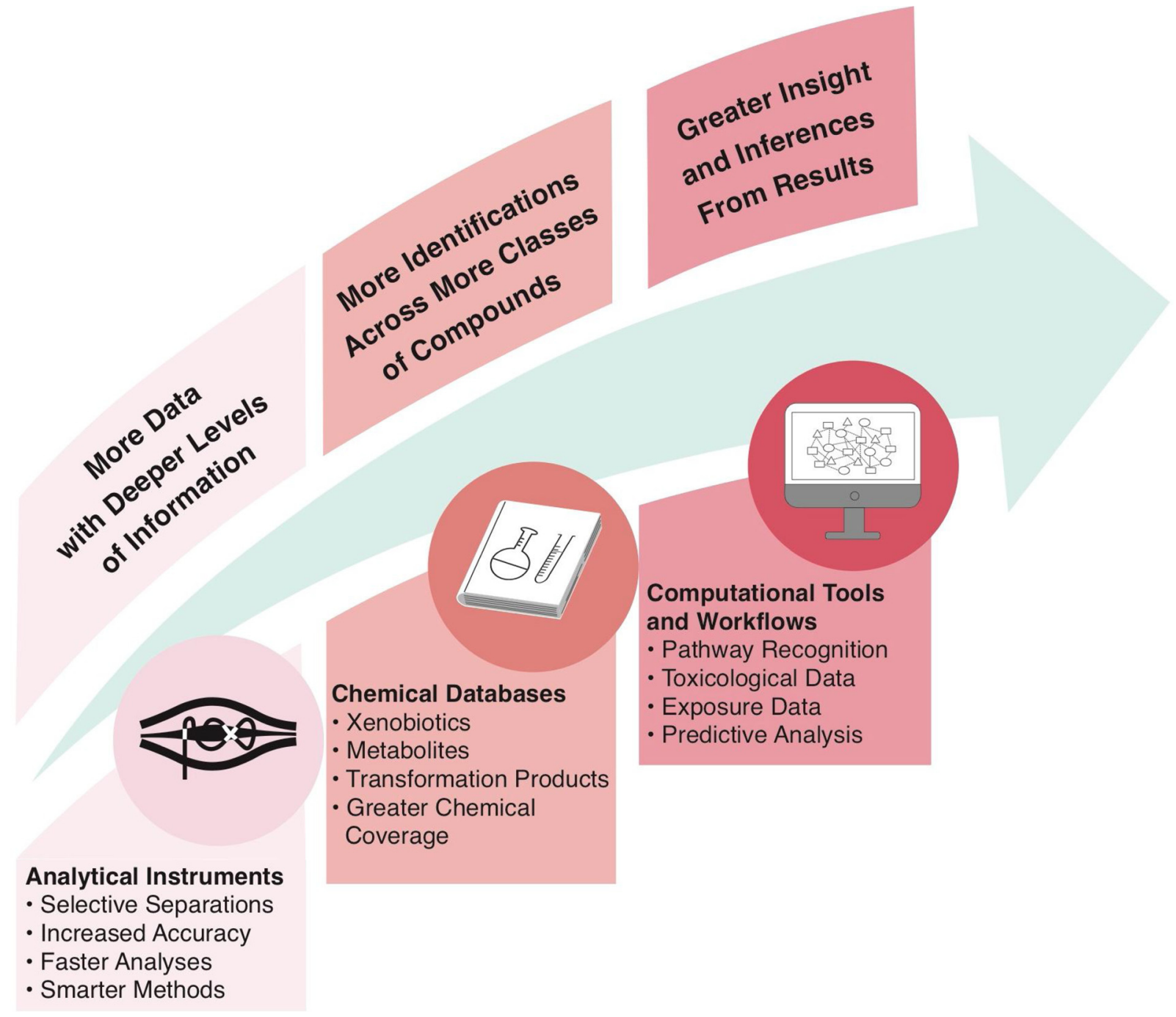

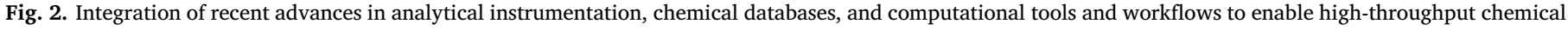
screening. The utilization of such integrative approaches will result in increased knowledge surrounding the fetal exposome.

advances in analytical and computational methods that support suspect screening and non-targeted analysis to more fully characterize the fetal exposome.

\subsection{Expanding methods to evaluate the environmental prenatal exposome}

Mass spectrometry (MS) platforms are the primary tools for both suspect screening and non-targeted analysis applications [113]. Suspect screening utilizes reference spectra for individual analytes that have been previously acquired on an MS platform and stored in an accessible library. In suspect screening studies, empirical spectra are acquired for unknown "features" (i.e., an aggregation of associated $\mathrm{m} / \mathrm{z}$ peaks) within a sample of interest, and then compared to library spectra to identify potential matches. All possible matches are scored based on the similarity between experimental and library spectra, with the best match (corroborated by manual review) often deemed a "tentative candidate" identification [114]. Additional (orthogonal) experimental data (e.g., retention behavior) may be used to elevate the tentative candidate to a "probable structure", but examination using a reference standard is ultimately needed to list a feature of interest as a "confirmed structure" [114].

Suspect screening is a popular technique for exposomic investigations, as it can be implemented using both GC and LC separation, and both low- and high-resolution MS detection. Low-resolution MS is well- suited for suspect screening when using GC with an electron ionization (EI) source. Unlike "soft" ionization techniques, EI-MS generates rich fragmentation spectra that can be readily used to identify tentative candidates in samples of interest. Massive libraries of reference EI spectra exist for hundreds-of-thousands of known substances [115]. Thus, GC EI-MS applications have broad reach when screening for the presence of small molecules that are relatively volatile and non-polar (e.g., PBDEs and select pesticides/herbicides). Conversely, LC-MS techniques are best suited when seeking a chemical space that is less volatile, more polar, and inclusive of larger compounds (e.g., conjugated xenobiotic metabolites, hormones, lipids, peptides, and select environmental compounds, including PFAS). Unlike most GC-based methods, LC-based methods utilize softer ionization techniques (e.g., electrospray ionization [ESI], atmospheric pressure chemical ionization [APCI]) that produce the molecular ion with limited in-source fragmentation. Tandem mass spectrometry techniques are therefore used to generate fragmentation spectra (i.e., MS/MS spectra) that can be compared to library spectra for tentative compound identification. Similar numbers of reference spectra exist when comparing EI-MS and soft-ionization MS/MS libraries [115]. Yet, far fewer substances are represented in MS/MS libraries, owing to the variable nature of parameters used for spectral acquisition.

In principle, suspect screening works best when reference spectra exist for compounds of interest in an accessible library. Yet, exposome 
studies routinely show the existence of large numbers of empirical features that do not match with library entries; these unmatched features are described as the "dark matter" of the exposome $[115,116]$. Non-targeted analysis is the appropriate technique for proposing formulae and eventually structures for these dark matter compounds. Whether using GC or LC separation, non-targeted analysis relies on high-resolution mass spectrometry (HRMS) with soft ionization techniques. Here, the accurate mass, isotope profile, and available fragmentation spectra corresponding to an unknown feature is first used to proffer one or more candidate molecular formulae for that feature. Next, databases of known chemical structures are queried using the tentatively assigned formula and/or the observed accurate mass. Individual databases like PubChem [117] and ChemSpider [118] contain structures for millions of known compounds, whereas the CompTox Chemicals Dashboard (hereafter called the "Dashboard") is "a one-stopshop for chemistry, toxicity and exposure information for over 875,000 chemicals" of interest to the US EPA [119]. Specific aspects of the Dashboard have been specifically developed to facilitate non-targeted analysis and help improve data organization, integration, and interpretation, making it a valuable resource for the exposomics community [119]. Articles describing this functionality and demonstrating enhancements to specific non-targeted analysis studies can be found in the published literature [7,120-122].

While non-targeted analysis can theoretically allow identification of millions of structures, many MS features remain unidentified even after exhaustive examination. Some of these unidentified features are byproducts of the analytical tools (e.g., adducts, multimers and in-source fragments) and may be partially addressed using stringent data filtering procedures [123]. Others are truly unknown substances that may be produced from environmental transformation or degradation processes, or metabolically-aided processes that occur within biological systems. Various computational tools exist that allow prediction of transformation products and/or metabolites given a list of expected parent compounds [124]. Other tools exist that allow prediction of theoretical spectra for these anticipated products/metabolites [125,126]. When used together, these tools enable the identification of truly novel compounds in priority media and can help shed light on the dark matter of the human exposome.

\subsection{Linking chemical exposures to toxicological responses and disease outcomes}

Many studies that have evaluated environmental chemicals reaching the prenatal exposome have focused on the targeted measurement of these chemicals, with some studies linking chemical measurements to disease outcomes. However, fewer studies have made full linkages between: (i) environmental measures, (ii) maternal/fetal health outcomes, and (iii) biological mechanisms of toxicity mechanisms underlying potential health outcomes. A more comprehensive understanding of how environmental exposures impact maternal and child health can be achieved by linking measured environmental chemicals that cross human placenta and cord blood with toxicological changes, elucidating mechanisms linking exposure to disease, and identifying biomarkers of exposure associated with adverse maternal and fetal health outcomes (Fig. 3). Select studies reviewed here implemented these types of approaches and aimed to anchor exposures to toxicological responses and disease outcomes.

Example studies that have evaluated prenatal exposure to iAs include research conducted in the Ron Pibul and Bangkok districts of Thailand, and in Gómez Palacio, Mexico that have associated internal exposure metrics to toxicological mechanisms of iAs-induced disease $[20,127]$. These studies related maternal iAs exposure through drinking water to altered gene expression profiles in newborn cord blood and related these to associated signaling pathways relevant to iAs-induced disease. More specifically, in Thailand, 11 transcripts in newborn cord blood were determined to be predictive biomarkers for iAs exposure and correlated with biological pathways including cell death, cell signaling, inflammation, and other stress responses [20,127]. Similarly, among the cohort in Mexico, iAs concentrations in maternal urine samples were found to be associated with differential expression of 334 transcripts, a portion of which were predicted to be regulated by epigenetic mediators. Pathway analysis resulted in the identification of similar signaling alterations including those associated with stress, inflammation, and cytokine activity. Interestingly, this study also found a decrease in the expression levels of genes involved in immune response, with general immunosuppression known to play a role known in diseases relevant to iAs exposure, such as increased risk of infectious disease and cancer [20].

In general, there are few studies that have employed mechanistic toxicology approaches to connect prenatal exposures to molecular mediators of disease. A recent example study evaluated the effects of prenatal exposure to PFAS and identified alterations in cord blood CpG methylation patterns within several genes, including those involved in endocrine system signaling, signal transduction, and immune signaling; though this research did not directly link these changes to observable health outcomes [128]. Future research that incorporates more toxicology-driven approaches, using in vitro, animal, and human study designs, can play an important role in elucidating how environmental exposures impact maternal and child health outcomes. The biological plausibility linking exposures to disease outcomes can be strengthened through in vitro methods aimed at identifying mechanisms of action, for instance through the systems biology-based approaches [129] and/or incorporation of recent genome editing technologies [130]. Indeed, many of the example chemicals discussed in this review have been examined across several models, including in vitro systems, and therefore have more robust information linking them to plausible adverse maternal and fetal health outcomes. Chemicals that are less studied, however, could significantly benefit from the inclusion of mechanistic toxicity studies, derived from several models, as well as human tissues. Such mechanistic-based studies will greatly contribute to the available evidence surrounding prenatal chemical exposures, toxicity responses, and adverse health outcomes.

\subsection{Other limitations and future directions}

The prenatal exposome represents an exciting area of investigation that is rapidly expanding to better address maternal and fetal health impacted by environmental chemicals. As reviewed above, there are many gaps that persist within this research field, including current limitations surrounding: (i) chemical coverage, (ii) anchorage of environmental monitoring data to toxicological endpoints, and (iii) related disease outcomes. Additionally, there remain limited data surrounding the temporality of exposome measures. Limited studies have evaluated how environmental chemicals and/or biomarkers of exposure change over time, particularly in biological matrices relevance to prenatal exposures and perinatal health. For example, the placenta represents a temporary organ that undergoes profound and dynamic changes in molecular expression, cell differentiation, structure, and function during pregnancy; causing the accumulation and impact of environmental chemicals on this organ to also change over time [62]. The majority of studies, to date, have focused on the evaluation of biological samples at a single point in time (i.e., biased towards time of infant birth). Studies could leverage the use of animal models or select alternative in vitro models to obtain information surrounding placenta and cord blood responses throughout pregnancy. In humans, other biological tissues could be used to inform issues surrounding temporality, including maternal blood and urine.

Data are also limited surrounding later-in-life health effects that could result from prenatal exposure conditions, with most studies evaluating effects during pregnancy or at birth. These obstetric outcomes are still critical endpoints to evaluate, as many of these are also associated with later-in-life health effects (e.g., associations between 


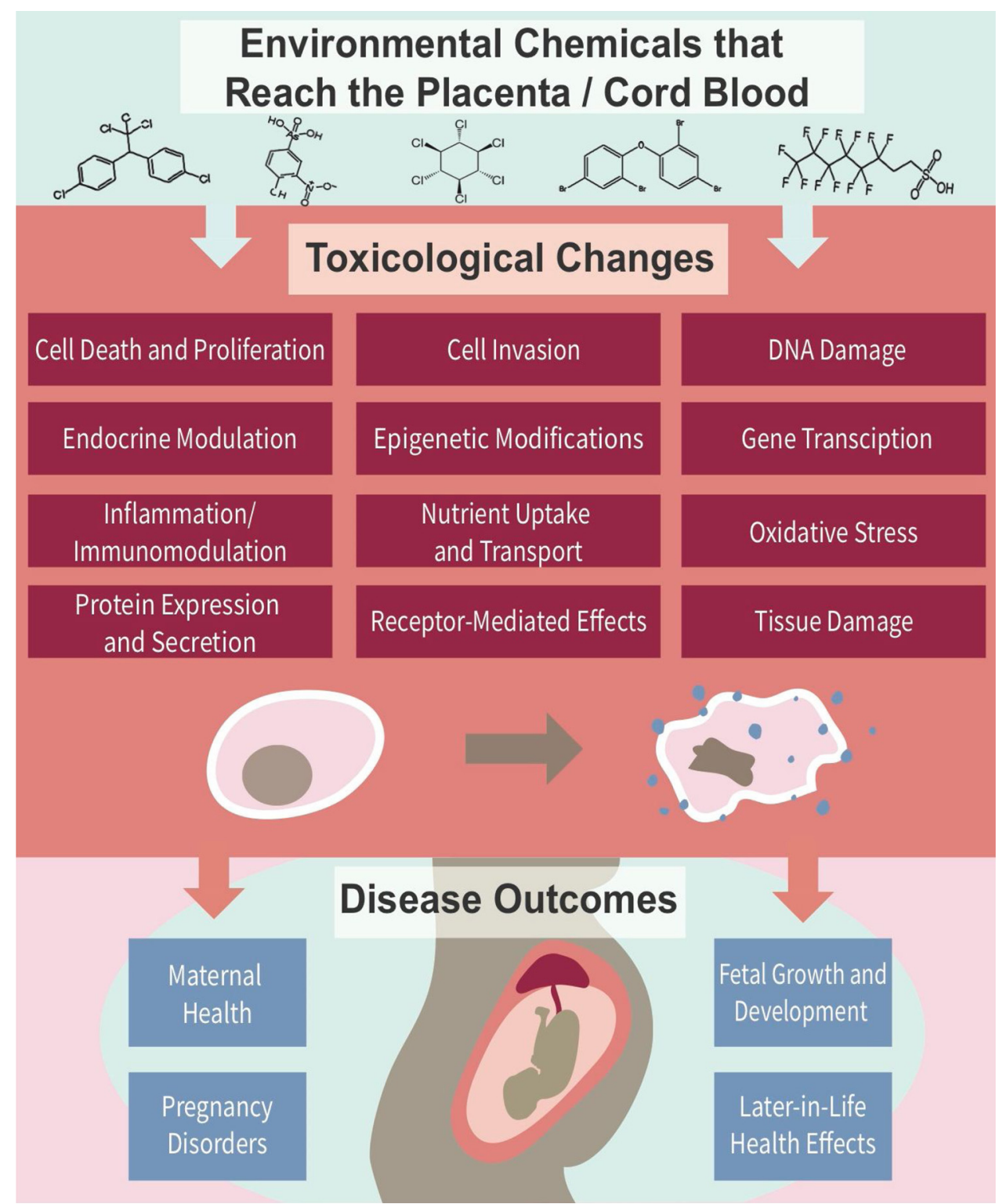

Fig. 3. Example toxicological endpoints and disease outcomes that can be related to measures of the prenatal exposome to better understand relationships and mechanisms underlying environmental exposure-induced disease.

preeclampsia / pre-term birth and suboptimal childhood neurodevelopment [131]). The influence of other factors that play a role in chemicals reaching the placenta/fetus, including genetics and sex-specific traits, also represents an important data gap. Other factors that potentially interact with and influence the prenatal exposome remain understudied, including nutrition and socioeconomic status. These research topics represent important areas that could be addressed in future studies through the implementation of aforementioned advances in analytical chemistry approaches, expanded epidemiological measures, toxicological endpoints, and temporal influences on exposures and disease outcomes.

\section{Conclusion}

In conclusion, this review provides an overview on environmental chemicals representing the prenatal exposome. Emphasis is placed on chemicals reaching the human placenta and cord blood, as these represent important target tissues that heavily regulate maternal and fetal health outcomes. Current studies have shown that certain classes of chemicals, including flame retardants, metals, pesticides and herbicides, PFAS, and toxins, have the potential to impact the maternal and fetal exposome. However, there is a lack of knowledge surrounding the global space of chemicals that may reach the human placenta and cord blood that could be addressed through non-targeted / suspect screening analytical approaches. Further studies are also needed to clearly link chemical exposures to potential adverse pregnancy and developmental toxicity outcomes. Advances in this field of research will significantly contribute towards the understanding of environmental chemicals in the fetal exposome and their impact on maternal and fetal health.

\section{Declaration of Competing Interest}

The authors have no conflict of interest.

\section{Acknowledgement}

This research was supported by grants from the National Institute of Environmental Health Sciences (P30ES010126, P42ES005948, R01MD011609). 


\section{References}

[1] C.P. Wild, Complementing the Genome With an "exposome": the Outstanding Challenge of Environmental Exposure Measurement in Molecular Epidemiology, AACR, 2005.

[2] S.M. Rappaport, M.T. Smith, Epidemiology. Environment and disease risks, Science 330 (6003) (2010) 460-461 Epub 2010/10/23. doi: 10.1126/science.1192603. PubMed PMID: 20966241; PMCID: PMC4841276.

[3] C.P. Wild, The exposome: from concept to utility, Int. J. Epidemiol. 41 (1) (2012) 24-32.

[4] D. Briggs, Environmental pollution and the global burden of disease, Br. Med. Bull. 68 (2003) 1-24, https://doi.org/10.1093/bmb/ldg019 Epub 2004/02/06, PubMed PMID: 14757707.

[5] P.P. Egeghy, R. Judson, S. Gangwal, S. Mosher, D. Smith, J. Vail, E.A. Cohen Hubal, The exposure data landscape for manufactured chemicals, Sci. Total Environ. 414 (2012) 159-166 Epub 2011/11/23. doi: 10.1016/j.scitotenv.2011.10.046. PubMed PMID: 22104386.

[6] R. Judson, A. Richard, D.J. Dix, K. Houck, M. Martin, R. Kavlock, V. Dellarco, T. Henry, T. Holderman, P. Sayre, S. Tan, T. Carpenter, E. Smith, The toxicity data landscape for environmental chemicals, Environ. Health Perspect. 117 (5) (2009) 685-695 Epub 2009/05/30. doi: 10.1289/ehp.0800168. PubMed PMID: 19479008; PMCID: PMC2685828.

[7] J.R. Sobus, J.F. Wambaugh, K.K. Isaacs, A.J. Williams, A.D. McEachran, A.M. Richard, C.M. Grulke, E.M. Ulrich, J.E. Rager, M.J. Strynar, S.R. Newton, Integrating tools for non-targeted analysis research and chemical safety evaluations at the US EPA, J. Expo. Sci. Environ. Epidemiol. 28 (5) (2018) 411-426 Epub 2017/12/31. doi: 10.1038/s41370-017-0012-y. PubMed PMID: 29288256.

[8] J.E. Rager, M.J. Strynar, S. Liang, R.L. McMahen, A.M. Richard, C.M. Grulke, J.F. Wambaugh, K.K. Isaacs, R. Judson, A.J. Williams, J.R. Sobus, Linking high resolution mass spectrometry data with exposure and toxicity forecasts to advance high-throughput environmental monitoring, Environ. Int. 88 (2016) 269-280 Epub 2016/01/27. doi: 10.1016/j.envint.2015.12.008. PubMed PMID: 26812473.

[9] C. Moschet, T. Anumol, B.M. Lew, D.H. Bennett, T.M. Young, Household dust as a repository of chemical accumulation: new insights from a comprehensive highresolution mass spectrometric study, Environ. Sci. Technol. 52 (5) (2018) 2878-2887 Epub 2018/02/14. doi: 10.1021/acs.est.7b05767. PubMed PMID: 29437387.

[10] X. Ouyang, J.M. Weiss, J. de Boer, M.H. Lamoree, P.E.G. Leonards, Non-target analysis of household dust and laundry dryer lint using comprehensive two-dimensional liquid chromatography coupled with time-of-flight mass spectrometry, Chemosphere. 166 (2017) 431-437 Epub 2016/10/06. doi: 10.1016/j.chemosphere.2016.09.107. PubMed PMID: 27705830.

[11] P. Rostkowski, P. Haglund, R. Aalizadeh, N. Alygizakis, N. Thomaidis, J.B. Arandes, P.B. Nizzetto, P. Booij, H. Budzinski, P. Brunswick, A. Covaci, C. Gallampois, S. Grosse, R. Hindle, I. Ipolyi, K. Jobst, S.L. Kaserzon, P. Leonards, F. Lestremau, T. Letzel, J. Magner, H. Matsukami, C. Moschet, P. Oswald, M. Plassmann, J. Slobodnik, C. Yang, The strength in numbers: comprehensive characterization of house dust using complementary mass spectrometric techniques, Anal. Bioanal. Chem. 411 (10) (2019) 1957-1977 Epub 2019/03/05. doi: 10.1007/s00216-019-01615-6. PubMed PMID: 30830245; PMCID: PMC6458998.

[12] S.R. Newton, R.L. McMahen, J.R. Sobus, K. Mansouri, A.J. Williams, A.D. McEachran, M.J. Strynar, Suspect screening and non-targeted analysis of drinking water using point-of-use filters, Environ Pollut. 234 (2018) 297-306 Epub 2017/11/29. doi: 10.1016/j.envpol.2017.11.033. PubMed PMID: 29182974; PMCID: PMC6145080.

[13] A.M. Brunner, Baken K.A. Dingemans MML, A.P. van Wezel, Prioritizing anthropogenic chemicals in drinking water and sources through combined use of mass spectrometry and ToxCast toxicity data, J. Hazard. Mater. 364 (2019) 332-338 Epub 2018/11/02. doi: 10.1016/j.jhazmat.2018.10.044. PubMed PMID: 30384243

[14] S.Y. Kimura, A.A. Cuthbertson, J.D. Byer, S.D. Richardson, The DBP exposome: development of a new method to simultaneously quantify priority disinfection byproducts and comprehensively identify unknowns, Water Res. 148 (2019) 324-333 Epub 2018/11/06. doi: 10.1016/j.watres.2018.10.057. PubMed PMID: 30391861.

[15] K.A. Phillips, A. Yau, K.A. Favela, K.K. Isaacs, A. McEachran, C. Grulke, A.M. Richard, A.J. Williams, J.R. Sobus, R.S. Thomas, J.F. Wambaugh, Suspect screening analysis of chemicals in consumer products, Environ. Sci. Technol. 52 (5) (2018) 3125-3135 Epub 2018/02/07. doi: 10.1021/acs.est.7b04781. PubMed PMID: 29405058; PMCID: PMC6168952.

[16] V. Bessonneau, J. Pawliszyn, S.M. Rappaport, The saliva exposome for monitoring of individuals' health trajectories, Environ. Health Perspect. 125 (7) (2017) 077014 Epub 2017/07/27. doi: 10.1289/EHP1011. PubMed PMID: 28743678; PMCID: PMC5801473.

[17] S.M. Rappaport, D.K. Barupal, D. Wishart, P. Vineis, A. Scalbert, The blood exposome and its role in discovering causes of disease, Environ. Health Perspect. 122 (8) (2014) 769-774.

[18] S.S. Andra, C. Austin, M. Arora, The tooth exposome in children's health research, Curr. Opin. Pediatr. 28 (2) (2016) 221-227 Epub 2016/02/10. doi: 10.1097/ MOP.0000000000000327. PubMed PMID: 26859286; PMCID: PMC4949598.

[19] D.P. Robinson, S.L. Klein, Pregnancy and pregnancy-associated hormones alter immune responses and disease pathogenesis, Horm. Behav. 62 (3) (2012) 263-271 Epub 2012/03/13. doi: 10.1016/j.yhbeh.2012.02.023. PubMed PMID: 22406114; PMCID: PMC3376705.

[20] J.E. Rager, K.A. Bailey, L. Smeester, S.K. Miller, J.S. Parker, J.E. Laine, Z. Drobna,
J. Currier, C. Douillet, A.F. Olshan, M. Rubio-Andrade, M. Styblo, G. GarciaVargas, R.C. Fry, Prenatal arsenic exposure and the epigenome: altered microRNAs associated with innate and adaptive immune signaling in newborn cord blood, Environ. Mol. Mutagen. 55 (3) (2014) 196-208 Epub 2013/12/12. doi: 10.1002/ em.21842. PubMed PMID: 24327377; PMCID: PMC4023469.

[21] D.R. Mattison, Environmental exposures and development, Curr. Opin. Pediatr. 22 (2) (2010) 208-218 Epub 2010/03/11. doi: 10.1097/MOP.0b013e32833779bf. PubMed PMID: 20216314; PMCID: PMC2887611..

[22] A.P. Kourtis, J.S. Read, D.J. Jamieson, Pregnancy and infection, N. Engl. J. Med. 370 (23) (2014) 2211-2218 Epub 2014/06/05. doi: 10.1056/NEJMra1213566. PubMed PMID: 24897084; PMCID: PMC4459512.

[23] E. Sappenfield, D.J. Jamieson, A.P. Kourtis, Pregnancy and susceptibility to infectious diseases, Infect. Dis. Obstet. Gynecol. 2013 (2013) 752852 Epub $2013 /$ 08/13. doi: 10.1155/2013/752852. PubMed PMID: 23935259; PMCID: PMC3723080.

[24] R.L. Brent, S. Tanski, M. Weitzman, A pediatric perspective on the unique vulnerability and resilience of the embryo and the child to environmental toxicants: the importance of rigorous research concerning age and agent, Pediatrics. 113 (4 Suppl) (2004) 935-944 Epub 2004/04/03. PubMed PMID: 15060185.

[25] A.J. Falck, S. Mooney, S.S. Kapoor, K.M. White, C. Bearer, D. El Metwally, Developmental exposure to environmental toxicants, Pediatr. Clin. North Am. 62 (5) (2015) 1173-1197 Epub 2015/09/01. doi: 10.1016/j.pcl.2015.05.005. PubMed PMID: 26318946.

[26] D.J. Hoffman, R.M. Reynolds, D.B. Hardy, Developmental origins of health and disease: current knowledge and potential mechanisms, Nutr. Rev. 75 (12) (2017) 951-970 Epub 2017/12/01. doi: 10.1093/nutrit/nux053. PubMed PMID: 29186623.

[27] J. McKinney, R. Rogers, ES\&T metal bioavailability, Environ. Sci. Technol. 26 (7) (1992) 1298-1299.

[28] L. Aylward, S. Hays, J. LaKind, J. Ryan, Rapid communication: partitioning of persistent lipophilic compounds, including dioxins, between human milk lipid and blood lipid: an initial assessment, J. Toxicol. Environ. Health Part A 66 (1) (2003) $1-5$.

[29] X. Han, T.A. Snow, R.A. Kemper, G.W. Jepson, Binding of perfluorooctanoic acid to rat and human plasma proteins, Chem. Res. Toxicol. 16 (6) (2003) 775-781.

[30] S.A. Peters, A.L. Ungell, H. Dolgos, Physiologically based pharmacokinetic (PBPK) modeling and simulation: applications in lead optimization, Curr. Opin. Drug Discov. Devel. 12 (4) (2009) 509-518 Epub 2009/06/30. PubMed PMID: 19562647.

[31] J.M. Conder, R.A. Hoke, Wolf Wd, M.H. Russell, R.C. Buck, Are PFCAs bioaccumulative? A critical review and comparison with regulatory criteria and persisten lipophilic compounds, Environ. Sci. Technol. 42 (4) (2008) 995-1003.

[32] H. Frederiksen, N.E. Skakkebaek, A.M. Andersson, Metabolism of phthalates in humans, Mol. Nutr. Food Res. 51 (7) (2007) 899-911.

[33] D.F. Kapraun, J.F. Wambaugh, R.W. Setzer, R.S. Judson, Empirical models for anatomical and physiological changes in a human mother and fetus during pregnancy and gestation, PLoS One 14 (5) (2019) e0215906 Epub 2019/05/03. doi: 10.1371/journal.pone.0215906. PubMed PMID: 31048866; PMCID: PMC6497258,

[34] L.L. Needham, P. Grandjean, B. Heinzow, P.J. Jørgensen, F. Nielsen, D.G. Patterson Jr, A. Sjödin, W.E. Turner, P. Weihe, Partition of environmental chemicals between maternal and fetal blood and tissues, Environ. Sci. Technol. 45 (3) (2010) 1121-1126.

[35] T. Eshkoli, E. Sheiner, Z. Ben-Zvi, G. Holcberg, Drug transport across the placenta, Curr. Pharm. Biotechnol. 12 (5) (2011) 707-714 Epub 2011/02/24. PubMed PMID: 21342126.

[36] S. Al-Enazy, S. Ali, N. Albekairi, M. El-Tawil, E. Rytting, Placental control of drug delivery, Adv. Drug Deliv. Rev. 116 (2017) 63-72 Epub 2016/08/17. doi: 10.1016/j.addr.2016.08.002. PubMed PMID: 27527665; PMCID: PMC5303687.

[37] L. Dock, R.L. Rissanen, M. Vahter, Demethylation and placental transfer of methyl mercury in the pregnant hamster, Toxicology 94 (1994) 131-142.

[38] M. Iqbal, M.C. Audette, S. Petropoulos, W. Gibb, S.G. Matthews, Placental drug transporters and their role in fetal protection, Placenta. 33 (3) (2012) 137-142 Epub 2012/01/24. doi: 10.1016/j.placenta.2012.01.008. PubMed PMID: 22265855.

[39] K.M. Bircsak, V. Gupta, P.Y. Yuen, L. Gorczyca, B.I. Weinberger, A.M. Vetrano, L.M. Aleksunes, Genetic and dietary regulation of glyburide efflux by the human placental breast Cancer resistance protein transporter, J. Pharmacol. Exp. Ther 357 (1) (2016) 103-113 Epub 2016/02/07. doi: 10.1124/jpet.115.230185. PubMed PMID: 26850786; PMCID: PMC4809313.

[40] J.T. Szilagyi, L. Gorczyca, A. Brinker, B. Buckley, J.D. Laskin, L.M. Aleksunes, Placental BCRP/ABCG2 transporter prevents fetal exposure to the estrogenic mycotoxin zearalenone, Toxicol. Sci. (2018) Epub 2018/12/24. doi: 10.1093/ toxsci/kfy303. PubMed PMID: 30576553.

[41] J. Xiao, Q. Wang, K.M. Bircsak, X. Wen, L.M. Aleksunes, In vitro screening of environmental chemicals identifies zearalenone as a novel substrate of the placental BCRP/ABCG2 transporter, Toxicol. Res. (Camb) 4 (3) (2015) 695-706 Epub 2015/06/09. doi: 10.1039/c4tx00147h. PubMed PMID: 26052432; PMCID PMC4452124.

[42] A. Wang, R.R. Gerona, J.M. Schwartz, T. Lin, M. Sirota, R. Morello-Frosch, T.J. Woodruff, A suspect screening method for characterizing multiple chemical exposures among a demographically diverse population of pregnant women in San Francisco, Environ. Health Perspect. 126 (7) (2018) 077009Epub 2018/07/26. doi: 10.1289/EHP2920. PubMed PMID: 30044231; PMCID: PMC6108847.

[43] R.R. Gerona, J.M. Schwartz, J. Pan, M.M. Friesen, T. Lin, T.J. Woodruff, Suspect screening of maternal serum to identify new environmenta chemica 
biomonitoring targets using liquid chromatography-quadrupole time-of-flight mass spectrometry, J. Expo. Sci. Environ. Epidemiol. 28 (2) (2018) 101-108 Epub 2017/10/12. doi: 10.1038/jes.2017.28. PubMed PMID: 29019345.

[44] A. Wang, A. Padula, M. Sirota, T.J. Woodruff, Environmental influences on reproductive health: the importance of chemical exposures, Fertil. Steril. 106 (4) (2016) 905-929 Epub 2016/08/12. doi: 10.1016/j.fertnstert.2016.07.1076. PubMed PMID: 27513554; PMCID: PMC5158104.

[45] Sciences NIoEH. Flame Retardant Fact Sheet, (2016) [cited 2019 April 11]. Available from: https://www.niehs.nih.gov/health/materials/flame_retardants_ 508.pdf.

[46] M. Frederiksen, M. Thomsen, K. Vorkamp, L.E. Knudsen, Patterns and concentration levels of polybrominated diphenyl ethers (PBDEs) in placental tissue of women in Denmark, Chemosphere 76 (11) (2009) 1464-1469 Epub 2009/08/18. doi: 10.1016/j.chemosphere.2009.07.017. PubMed PMID: 19682725.

[47] M. Frederiksen, C. Thomsen, M. Froshaug, K. Vorkamp, M. Thomsen, G. Becher, L.E. Knudsen, Polybrominated diphenyl ethers in paired samples of maternal and umbilical cord blood plasma and associations with house dust in a Danish cohort, Int. J. Hyg. Environ. Health 213 (4) (2010) 233-242 Epub 2010/05/18. doi: 10.1016/j.ijheh.2010.04.008. PubMed PMID: 20471317.

[48] B. Eskenazi, J. Chevrier, S.A. Rauch, K. Kogut, K.G. Harley, C. Johnson, C. Trujillo, A. Sjodin, A. Bradman, In utero and childhood polybrominated diphenyl ether (PBDE) exposures and neurodevelopment in the CHAMACOS study, Environ. Health Perspect. 121 (2) (2013) 257-262 Epub 2012/11/17. doi: 10.1289/ ehp.1205597. PubMed PMID: 23154064; PMCID: PMC3569691.

[49] S.D. Mitro, T. Johnson, A.R. Zota, Cumulative chemical exposures during pregnancy and early development, Curr. Environ. Health Rep. 2 (4) (2015) 367-378 Epub 2015/09/06. doi: 10.1007/s40572-015-0064-x. PubMed PMID: 26341623; PMCID: PMC4626367.

[50] J.P. Antignac, R. Cariou, D. Zalko, A. Berrebi, J.P. Cravedi, D. Maume, P. Marchand, F. Monteau, A. Riu, F. Andre, B. Le Bizec, Exposure assessment of French women and their newborn to brominated flame retardants: determination of tri- to deca- polybromodiphenylethers (PBDE) in maternal adipose tissue, serum, breast milk and cord serum, Environ Pollut. 157 (1) (2009) 164-173 Epub 2008/09/23. doi: 10.1016/j.envpol.2008.07.008. PubMed PMID: 18804904.

[51] Polder A. Muller MHB, O.B. Brynildsrud, R. Gronnestad, M. Karimi, E. Lie, W.B. Manyilizu, R.H. Mdegela, F. Mokiti, M. Murtadha, H.E. Nonga, J.U. Skaare, A. Solhaug, J.L. Lyche, Prenatal exposure to persistent organic pollutants in Northern Tanzania and their distribution between breast milk, maternal blood, placenta and cord blood, Environ. Res. 170 (2019) 433-442 Epub 2019/01/12. doi: 10.1016/j.envres.2018.12.026. PubMed PMID: 30634139.

[52] J.B. Herbstman, A. Sjodin, M. Kurzon, S.A. Lederman, R.S. Jones, V. Rauh, L.L. Needham, D. Tang, M. Niedzwiecki, R.Y. Wang, F. Perera, Prenatal exposure to PBDEs and neurodevelopment, Environ. Health Perspect. 118 (5) (2010) 712-719 Epub 2010/01/09. doi: 10.1289/ehp.0901340. PubMed PMID: 20056561; PMCID: PMC2866690.

[53] C.M. Butt, M.L. Miranda, H.M. Stapleton, Development of an analytical method to quantify PBDEs, OH-BDEs, HBCDs, 2, 4, 6-TBP, EH-TBB, and BEH-TEBP in human serum, Anal. Bioanal. Chem. 408 (10) (2016) 2449-2459.

[54] J.F. Brown, R.W. Lawton, Polychlorinated biphenyl (PCB) partitioning between adipose tissue and serum, Bull. Environ. Contam. Toxicol. 33 (1) (1984) 277-280.

[55] A. Schecter, M. Pavuk, O. Päpke, J.J. Ryan, L. Birnbaum, R. Rosen, Polybrominated diphenyl ethers (PBDEs) in US mothers' milk, Environ. Health Perspect. 111 (14) (2003) 1723-1729.

[56] T. Punshon, M.A. Davis, C.J. Marsit, S.K. Theiler, E.R. Baker, B.P. Jackson, D.C. Conway, M.R. Karagas, Placental arsenic concentrations in relation to both maternal and infant biomarkers of exposure in a US cohort, J. Expo. Sci. Environ. Epidemiol. 25 (6) (2015) 599-603 Epub 2015/03/26. doi: 10.1038/jes.2015.16. PubMed PMID: 25805251; PMCID: PMC4583336.

[57] M. Piasek, A. Mikolic, A. Sekovanic, A. Sulimanec Grgec, J. Jurasovic, Cadmium in placenta- a valuable biomarker of exposure during pregnancy in biomedical research, J Toxicol Environ Health A. 77 (18) (2014) 1071-1074 Epub 2014/07/30. doi: 10.1080/15287394.2014.915779. PubMed PMID: 25072893.

[58] I. Al-Saleh, N. Shinwari, A. Mashhour, D. Mohamed Gel, A. Rabah, Heavy metals (lead, cadmium and mercury) in maternal, cord blood and placenta of healthy women, Int. J. Hyg. Environ. Health 214 (2) (2011) 79-101 Epub 2010/11/26. doi: 10.1016/j.ijheh.2010.10.001. PubMed PMID: 21093366.

[59] C.L. Gilman, R. Soon, L. Sauvage, N.V. Ralston, M.J. Berry, Umbilical cord blood and placental mercury, selenium and selenoprotein expression in relation to maternal fish consumption, J. Trace Elem. Med. Biol. 30 (2015) 17-24 Epub 2015/ 03/10. doi: 10.1016/j.jtemb.2015.01.006. PubMed PMID: 25744505; PMCID: PMC4352208.

[60] J.E. Rager, S.K. Tilley, S.E. Tulenko, L. Smeester, P.D. Ray, A. Yosim, J.M. Currier, M.C. Ishida, C. Gonzalez-Horta Mdel, B. Sanchez-Ramirez, L. Ballinas-Casarrubias, D.S. Gutierrez-Torres, Z. Drobna, L.M. Del Razo, G.G. Garcia-Vargas, W.Y. Kim, Y.H. Zhou, F.A. Wright, M. Styblo, R.C. Fry, Identification of novel gene targets and putative regulators of arsenic-associated DNA methylation in human urothelial cells and bladder cancer, Chem. Res. Toxicol. 28 (6) (2015) 1144-1155 Epub 2015/06/04. doi: 10.1021/tx500393y. PubMed PMID: 26039340; PMCID: PMC4748849.

[61] M. Hall, M. Gamble, V. Slavkovich, X. Liu, D. Levy, Z. Cheng, A. van Geen, M. Yunus, M. Rahman, J.R. Pilsner, J. Graziano, Determinants of arsenic metabolism: blood arsenic metabolites, plasma folate, cobalamin, and homocysteine concentrations in maternal-newborn pairs, Environ. Health Perspect. 115 (10) (2007) 1503-1509 Epub 2007/10/17. doi: 10.1289/ehp.9906. PubMed PMID: 17938743; PMCID: PMC2022678.

[62] T. Jacobo-Estrada, M. Santoyo-Sanchez, F. Thevenod, Barbier O. Cadmium
Handling, Toxicity and molecular targets involved during pregnancy: lessons from experimental models, Int. J. Mol. Sci. 18 (7) (2017) Epub 2017/07/25. doi: 10.3390/ijms18071590. PubMed PMID: 28737682; PMCID: PMC5536077.

[63] E.E. Brako, A.K. Wilson, M.M. Jonah, C.A. Blum, E.A. Cerny, K.L. Williams, M.H. Bhattacharyya, Cadmium pathways during gestation and lactation in control versus metallothoinein 1,2-knockout mice, Toxicol. Sci. 71 (2) (2003) 154-163 Epub 2003/02/04. PubMed PMID: 12563101.

[64] N.B. Patel, Y. Xu, L.C. McCandless, A. Chen, K. Yolton, J. Braun, R.L. Jones, K.N. Dietrich, B.P. Lanphear, Very low-level prenatal mercury exposure and behaviors in children: the HOME Study, Environ. Health 18 (1) (2019) 4 Epub 2019/ 01/11. doi: 10.1186/s12940-018-0443-5. PubMed PMID: 30626382; PMCID: PMC6325670.

[65] K.M. Wai, O. Mar, S. Kosaka, M. Umemura, C. Watanabe, Prenatal heavy metal exposure and adverse birth outcomes in Myanmar: a birth-cohort study, Int. J. Environ. Res. Public Health 14 (11) (2017) Epub 2017/11/04. doi: 10.3390/ ijerph14111339. PubMed PMID: 29099808; PMCID: PMC5707978.

[66] P.A. Bommarito, E. Martin, R.C. Fry, Effects of prenatal exposure to endocrine disruptors and toxic metals on the fetal epigenome, Epigenomics 9 (3) (2017) 333-350 Epub 2017/02/25. doi: 10.2217/epi-2016-0112. PubMed PMID: 28234024; PMCID: PMC5827796.

[67] P.I. Bank-Nielsen, M. Long, E.C. Bonefeld-Jorgensen, Pregnant inuit women's exposure to metals and association with fetal growth outcomes: ACCEPT 2010(-) 2015, Int. J. Environ. Res. Public Health 16 (7) (2019) Epub 2019/04/04. doi 10.3390/ijerph16071171. PubMed PMID: 30939809; PMCID: PMC6479494.

[68] J.E. Laine, K.A. Bailey, M. Rubio-Andrade, A.F. Olshan, L. Smeester, Z. Drobna, A.H. Herring, M. Styblo, G.G. Garcia-Vargas, R.C. Fry, Maternal arsenic exposure, arsenic methylation efficiency, and birth outcomes in the Biomarkers of Exposure to ARsenic (BEAR) pregnancy cohort in Mexico, Environ. Health Perspect. 123 (2) (2015) 186-192 Epub 2014/10/18. doi: 10.1289/ehp.1307476. PubMed PMID: 25325819; PMCID: PMC4314242.

[69] D. Rojas, J.E. Rager, L. Smeester, K.A. Bailey, Z. Drobna, M. Rubio-Andrade, M. Styblo, G. Garcia-Vargas, R.C. Fry, Prenatal arsenic exposure and the epigenome: identifying sites of 5-methylcytosine alterations that predict functional changes in gene expression in newborn cord blood and subsequent birth outcomes, Toxicol. Sci. 143 (1) (2015) 97-106 Epub 2014/10/12. doi: 10.1093/toxsci/ kfu210. PubMed PMID: 25304211; PMCID: PMC4274382.

[70] C.D. Salpietro, S. Gangemi, P.L. Minciullo, S. Briuglia, M.V. Merlino, A. Stelitano, M. Cristani, D. Trombetta, A. Saija, Cadmium concentration in maternal and cord blood and infant birth weight: a study on healthy non-smoking women, J. Perinat. Med. 30 (5) (2002) 395-399 Epub 2002/11/22. doi: 10.1515/JPM.2002.061. PubMed PMID: 12442603.

[71] C. Gundacker, M. Hengstschlager, The role of the placenta in fetal exposure to heavy metals, Wien. Med. Wochenschr. 162 (9-10) (2012) 201-206 Epub 2012/ 06/22. doi: 10.1007/s10354-012-0074-3. PubMed PMID: 22717874.

[72] A. Rahman, P. Kumarathasan, J. Gomes, Infant and mother related outcomes from exposure to metals with endocrine disrupting properties during pregnancy, Sci. Total Environ. 569-570 (2016) 1022-1031 Epub 2016/07/06. doi: 10.1016/ j.scitotenv.2016.06.134. PubMed PMID: 27378155.

[73] Registry AfTSaD. Public Health Statement for DDT, DDE, and DDD Center for Disease Control and Prevention, (2002) [cited 2019 April 15]. Available from: https://www.atsdr.cdc.gov/phs/phs.asp?id $=79 \&$ tid $=20$.

[74] P. Dewan, V. Jain, P. Gupta, B.D. Banerjee, Organochlorine pesticide residues in maternal blood, cord blood, placenta, and breastmilk and their relation to birth size, Chemosphere 90 (5) (2013) 1704-1710 Epub 2012/11/13. doi: $10.1016 /$ j.chemosphere.2012.09.083. PubMed PMID: 23141556.

[75] L.L. Needham, P. Grandjean, B. Heinzow, P.J. Jorgensen, F. Nielsen, D.G. Patterson Jr., A. Sjodin, W.E. Turner, P. Weihe, Partition of environmental chemicals between maternal and fetal blood and tissues, Environ. Sci. Technol. 45 (3) (2011) 1121-1126 Epub 2010/12/21. doi: 10.1021/es1019614. PubMed PMID: 21166449; PMCID: PMC3031182.

[76] M. Fisher, T.E. Arbuckle, C.L. Liang, A. LeBlanc, E. Gaudreau, W.G. Foster, D. Haines, K. Davis, W.D. Fraser, Concentrations of persistent organic pollutants in maternal and cord blood from the maternal-infant research on environmental chemicals (MIREC) cohort study, Environ. Health 15 (1) (2016) 59 Epub 2016/05/ 05. doi: 10.1186/s12940-016-0143-y. PubMed PMID: 27142700; PMCID: PMC4855498.

[77] R.M. Whyatt, D. Camann, F.P. Perera, V.A. Rauh, D. Tang, P.L. Kinney, R. Garfinkel, H. Andrews, L. Hoepner, D.B. Barr, Biomarkers in assessing residential insecticide exposures during pregnancy and effects on fetal growth, Toxicol. Appl. Pharmacol. 206 (2) (2005) 246-254 Epub 2005/06/22. doi: 10.1016/j.taap.2004.11.027. PubMed PMID: 15967215.

[78] R.M. Whyatt, V. Rauh, D.B. Barr, D.E. Camann, H.F. Andrews, R. Garfinkel, L.A. Hoepner, D. Diaz, J. Dietrich, A. Reyes, D. Tang, P.L. Kinney, F.P. Perera, Prenatal insecticide exposures and birth weight and length among an urban minority cohort, Environ. Health Perspect. 112 (10) (2004) 1125-1132 Epub 2004/07/09. doi: 10.1289/ehp.6641. PubMed PMID: 15238288; PMCID: PMC1247388.

[79] M.K. Silver, J. Shao, C. Ji, B. Zhu, L. Xu, M. Li, M. Chen, Y. Xia, N. Kaciroti, B. Lozoff, J.D. Meeker, Prenatal organophosphate insecticide exposure and infant sensory function, Int. J. Hyg. Environ. Health 221 (3) (2018) 469-478 Epub 2018/ 02/07. doi: 10.1016/j.ijheh.2018.01.010. PubMed PMID: 29402694; PMCID: PMC5902422.

[80] V.A. Rauh, W.E. Garcia, R.M. Whyatt, M.K. Horton, D.B. Barr, E.D. Louis, Prenatal exposure to the organophosphate pesticide chlorpyrifos and childhood tremor, Neurotoxicology 51 (2015) 80-86 Epub 2015/09/20. doi: 10.1016/ j.neuro.2015.09.004. PubMed PMID: 26385760; PMCID: PMC4809635. 
[81] P. Kongtip, N. Nankongnab, R. Phupancharoensuk, C. Palarach, D. Sujirarat, S. Sangprasert, M. Sermsuk, N. Sawattrakool, S.R. Woskie, Glyphosate and paraquat in maternal and fetal serums in Thai women, J. Agromed. 22 (3) (2017) 282-289 Epub 2017/04/20. doi: 10.1080/1059924X.2017.1319315. PubMed PMID: 28422580.

[82] S. KEMI, Occurrence and Use of Highly Fluorinated Substances and Alternatives, Swedish Chemicals Agency Stockholm, Sweden, 2015.

[83] R. Monroy, K. Morrison, K. Teo, S. Atkinson, C. Kubwabo, B. Stewart, W.G. Foster, Serum levels of perfluoroalkyl compounds in human maternal and umbilical cord blood samples, Environ. Res. 108 (1) (2008) 56-62.

[84] G. Patlewicz, A.M. Richard, A.J. Williams, C.M. Grulke, R. Sams, J. Lambert, P.D. Noyes, M.J. DeVito, R.N. Hines, M. Strynar, A. Guiseppi-Elie, R.S. Thomas, A chemical category-based prioritization approach for selecting 75 per- and polyfluoroalkyl substances (PFAS) for tiered toxicity and toxicokinetic testing, Environ. Health Perspect. 127 (1) (2019) 14501 Epub 2019/01/12. doi: 10.1289/ EHP4555. PubMed PMID: 30632786.

[85] L.A. MacManus-Spencer, M.L. Tse, P.C. Hebert, H.N. Bischel, R.G. Luthy, Binding of Perfluorocarboxylates to serum albumin: a comparison of analytical methods, Anal. Chem. 82 (3) (2010) 974-981, https://doi.org/10.1021/ac902238u.

[86] C.A. Ng, K. Hungerbühler, Bioconcentration of Perfluorinated Alkyl Acids: How Important Is Specific Binding? Environ. Sci. Technol. 47 (13) (2013) 7214-7223, https://doi.org/10.1021/es400981a.

87] A. Glynn, U. Berger, A. Bignert, S. Ullah, M. Aune, S. Lignell, P.O. Darnerud, Perfluorinated alkyl acids in blood serum from primiparous women in Sweden: serial sampling during pregnancy and nursing, and temporal trends 1996-2010, Environ. Sci. Technol. 46 (16) (2012) 9071-9079.

[88] M.G. Porpora, R. Lucchini, A. Abballe, A.M. Ingelido, S. Valentini, E. Fuggetta, V. Cardi, A. Ticino, V. Marra, A.R. Fulgenzi, Placental transfer of persistent organic pollutants: a preliminary study on mother-newborn pairs, Int. J. Environ. Res. Public Health 10 (2) (2013) 699-711.

[89] J.T. Szilagyi, G.M. Composto-Wahler, L.B. Joseph, B. Wang, T. Rosen, J.D. Laskin, L.M. Aleksunes, Anandamide down-regulates placental transporter expression through CB2 receptor-mediated inhibition of cAMP synthesis, Pharmacol. Res. 141 (2019) 331-342, https://doi.org/10.1016/j.phrs.2019.01.002.

[90] Y. Zhang, S. Beesoon, L. Zhu, J.W. Martin, Biomonitoring of perfluoroalkyl acids in human urine and estimates of biological half-life, Environ. Sci. Technol. 47 (18) (2013) 10619-10627.

[91] K.B. Gützkow, L.S. Haug, C. Thomsen, A. Sabaredzovic, G. Becher, G. Brunborg, Placental transfer of perfluorinated compounds is selective-a Norwegian Mother and Child sub-cohort study, Int. J. Hyg. Environ. Health 215 (2) (2012) 216-219.

[92] S. Kim, K. Choi, K. Ji, J. Seo, Y. Kho, J. Park, S. Kim, S. Park, I. Hwang, J. Jeon, Trans-placental transfer of thirteen perfluorinated compounds and relations with fetal thyroid hormones, Environ. Sci. Technol. 45 (17) (2011) 7465-7472.

[93] B. Eryasa, P. Grandjean, F. Nielsen, D. Valvi, D. Zmirou-Navier, E. Sunderland, P. Weihe, Y. Oulhote, Physico-chemical properties and gestational diabetes predict transplacental transfer and partitioning of perfluoroalkyl substances, Environ. Int. 130 (2019) 104874, , https://doi.org/10.1016/j.envint.2019.05.068.

[94] L.S. Mamsen, R.D. Björvang, D. Mucs, M.-T. Vinnars, N. Papadogiannakis, C.H. Lindh, C.Y. Andersen, P. Damdimopoulou, Concentrations of perfluoroalkyl substances (PFASs) in human embryonic and fetal organs from first, second, and third trimester pregnancies, Environ. Int. 124 (2019) 482-492.

[95] T.E. Arbuckle, C. Kubwabo, M. Walker, K. Davis, K. Lalonde, I. Kosarac, S.W. Wen, D.L. Arnold, Umbilical cord blood levels of perfluoroalkyl acids and polybrominated flame retardants, Int. J. Hyg. Environ. Health 216 (2) (2013) 184-194.

[96] S. Itoh, A. Araki, T. Mitsui, C. Miyashita, H. Goudarzi, S. Sasaki, K. Cho, H. Nakazawa, Y. Iwasaki, N. Shinohara, Association of perfluoroalkyl substances exposure in utero with reproductive hormone levels in cord blood in the Hokkaido Study on Environment and Children's Health, Environ. Int. 94 (2016) 51-59.

[97] M.-S. Tsai, C.-C. Lin, M.-H. Chen, W.-S. Hsieh, P.-C. Chen, Perfluoroalkyl substances and thyroid hormones in cord blood, Environ. Pollut. 222 (2017) 543-548.

[98] I.-J. Wang, W.-S. Hsieh, C.-Y. Chen, T. Fletcher, G.-W. Lien, H.-L. Chiang, C.F. Chiang, T.-N. Wu, P.-C. Chen, The effect of prenatal perfluorinated chemicals exposures on pediatric atopy, Environ. Res. 111 (6) (2011) 785-791.

[99] M.-H. Chen, E.-H. Ha, H.-F. Liao, S.-F. Jeng, Y.-N. Su, T.-W. Wen, G.-W. Lien, C. Y. Chen, W.-S. Hsieh, P.-C. Chen, Perfluorinated compound levels in cord blood and neurodevelopment at 2 years of age, Epidemiology 24 (6) (2013) 800-808.

[100] K.M. Rappazzo, E. Coffman, E.P. Hines, Exposure to perfluorinated alkyl substances and health outcomes in children: a systematic review of the epidemiologic literature, Int. J. Environ. Res. Public Health 14 (7) (2017) 691.

[101] A. Ode, K. Källén, P. Gustafsson, L. Rylander, B.A. Jönsson, P. Olofsson, S.A. Ivarsson, C.H. Lindh, A. Rignell-Hydbom, Fetal exposure to perfluorinated compounds and attention deficit hyperactivity disorder in childhood, PLoS One 9 (4) (2014) e95891.

[102] D.V. Jensen, J. Christensen, H.E. Virtanen, N.E. Skakkebæk, K.M. Main, J. Toppari, C.W. Veje, A.-M. Andersson, F. Nielsen, P. Grandjean, No association between exposure to perfluorinated compounds and congenital cryptorchidism: a nested case-control study among 215 boys from Denmark and Finland, Reproduction. 147 (4) (2014) 411-417.

[103] K. Inoue, F. Okada, R. Ito, S. Kato, S. Sasaki, S. Nakajima, A. Uno, Y. Saijo, F. Sata, Y. Yoshimura, Perfluorooctane sulfonate (PFOS) and related perfluorinated compounds in human maternal and cord blood samples: assessment of PFOS exposure in a susceptible population during pregnancy, Environ. Health Perspect. 112 (11) (2004) 1204

[104] P. Belli, C. Bellaton, J. Durand, S. Balleydier, N. Milhau, M. Mure, J.F. Mornex, M. Benahmed, C. Le Jan, Fetal and neonatal exposure to the mycotoxin zearalenone induces phenotypic alterations in adult rat mammary gland, Food Chem.
Toxicol. 48 (10) (2010) 2818-2826 Epub 2010/07/20. doi: 10.1016/ j.fct.2010.07.012. PubMed PMID: 20637251

[105] L. Hilakivi-Clarke, E. Cho, R. Clarke, Maternal genistein exposure mimics the effects of estrogen on mammary gland development in female mouse offspring, Oncol. Rep. 5 (3) (1998) 609-616 Epub 1998/05/09. PubMed PMID: 9538161.

[106] J.T. Szilagyi, L. Gorczyca, A. Brinker, B. Buckley, J.D. Laskin, L.M. Aleksunes, Placental BCRP/ABCG2 transporter prevents fetal exposure to the estrogenic mycotoxin zearalenone, Toxicol. Sci. 168 (2) (2019) 394-404 Epub 2018/12/24. doi: 10.1093/toxsci/kfy303. PubMed PMID: 30576553.

[107] E.H. Rogers, R.D. Zehr, M.I. Gage, A.R. Humpage, I.R. Falconer, M. Marr, N. Chernoff, The cyanobacterial toxin, cylindrospermopsin, induces fetal toxicity in the mouse after exposure late in gestation, Toxicon. 49 (6) (2007) 855-864 Epub 2007/02/13. doi: 10.1016/j.toxicon.2006.12.009. PubMed PMID: 17292934.

[108] P.B. Wangikar, P. Dwivedi, N. Sinha, Effect in rats of simultaneous prenatal exposure to ochratoxin A and aflatoxin B1. I. Maternal toxicity and fetal malformations, Birth Defects Res. B Dev. Reprod. Toxicol. 71 (6) (2004) 343-351 Epub 2004/12/24. doi: 10.1002/bdrb.20021. PubMed PMID: 15617020.

[109] G. Biasucci, G. Calabrese, R. Di Giuseppe, G. Carrara, F. Colombo, B. Mandelli, M. Maj, T. Bertuzzi, A. Pietri, F. Rossi, The presence of ochratoxin A in cord serum and in human milk and its correspondence with maternal dietary habits, Eur. J. Nutr. 50 (3) (2011) 211-218 Epub 2010/09/03. doi: 10.1007/s00394-010-0130y. PubMed PMID: 20812016.

[110] F.E. Jonsyn, S.M. Maxwell, R.G. Hendrickse, Human fetal exposure to ochratoxin A and aflatoxins, Ann. Trop. Paediatr. 15 (1) (1995) 3-9 Epub 1995/01/01. PubMed PMID: 7598434.

[111] J. Hollender, E.L. Schymanski, H.P. Singer, P.L. Ferguson, Nontarget Screening with High Resolution Mass Spectrometry in the Environment: Ready to Go? Environ. Sci. Technol. 51 (20) (2017) 11505-11512 Epub 2017/09/07. doi: 10.1021/acs.est.7b02184. PubMed PMID: 28877430.

[112] T.E. Arbuckle, W.D. Fraser, M. Fisher, K. Davis, C.L. Liang, N. Lupien, S. Bastien, M.P. Velez, P. von Dadelszen, D.G. Hemmings, J. Wang, M. Helewa, S. Taback, M. Sermer, W. Foster, G. Ross, P. Fredette, G. Smith, M. Walker, R. Shear, L. Dodds, A.S. Ettinger, J.P. Weber, M. D'Amour, M. Legrand, P. Kumarathasan, R. Vincent, Z.C. Luo, R.W. Platt, G. Mitchell, N. Hidiroglou, K. Cockell, M. Villeneuve, D.F. Rawn, R. Dabeka, X.L. Cao, A. Becalski, N. Ratnayake, G. Bondy, X. Jin, Z. Wang, S. Tittlemier, P. Julien, D. Avard, H. Weiler, A. Leblanc, G. Muckle, M. Boivin, G. Dionne, P. Ayotte, B. Lanphear, J.R. Seguin, D. SaintAmour, E. Dewailly, P. Monnier, G. Koren, E. Ouellet, Cohort profile: the maternal infant research on environmental chemicals research platform, Paediatr. Perinat. Epidemiol. 27 (4) (2013) 415-425 Epub 2013/06/19. doi: 10.1111/ppe.12061. PubMed PMID: 23772943.

[113] S.S. Andra, C. Austin, D. Patel, G. Dolios, M. Awawda, M. Arora, Trends in the application of high-resolution mass spectrometry for human biomonitoring: an analytical primer to studying the environmental chemical space of the human exposome, Environ. Int. 100 (2017) 32-61 Epub 2017/01/08. doi: 10.1016/j.envint.2016.11.026. PubMed PMID: 28062070; PMCID: PMC5322482.

[114] E.L. Schymanski, J. Jeon, R. Gulde, K. Fenner, M. Ruff, H.P. Singer, J. Hollender, Identifying small molecules via high resolution mass spectrometry: communicating confidence, Environ. Sci. Technol. 48 (4) (2014) 2097-2098 Epub 2014/ 01/31. doi: 10.1021/es5002105. PubMed PMID: 24476540.

[115] B.Y.L. Peisl, E.L. Schymanski, P. Wilmes, Dark matter in host-microbiome metabolomics: tackling the unknowns-A review, Anal. Chim. Acta 1037 (2018) 13-27 Epub 2018/10/08. doi: 10.1016/j.aca.2017.12.034. PubMed PMID: 30292286.

[116] R.R. da Silva, P.C. Dorrestein, R.A. Quinn, Illuminating the dark matter in metabolomics, Proc. Natl. Acad. Sci. U. S. A. 112 (41) (2015) 12549-12550 Epub 2015/ 10/03. doi: 10.1073/pnas.1516878112. PubMed PMID: 26430243; PMCID: PMC4611607.

[117] S. Kim, J. Chen, T. Cheng, A. Gindulyte, J. He, S. He, Q. Li, B.A. Shoemaker, P.A. Thiessen, B. Yu, L. Zaslavsky, J. Zhang, E.E. Bolton, PubChem 2019 update: improved access to chemical data, Nucleic Acids Res. 47 (D1) (2019) D1102-D9. Epub 2018/10/30. doi: 10.1093/nar/gky1033. PubMed PMID: 30371825; PMCID: PMC6324075.

[118] A.J. Williams, ChemSpider, (2015).

[119] A.J. Williams, C.M. Grulke, J. Edwards, A.D. McEachran, K. Mansouri, N.C. Baker, G. Patlewicz, I. Shah, J.F. Wambaugh, R.S. Judson, A.M. Richard, The CompTox Chemistry Dashboard: a community data resource for environmental chemistry, J. Cheminform. 9 (1) (2017) 61 Epub 2017/12/01. doi: 10.1186/s13321-017-0247 6. PubMed PMID: 29185060; PMCID: PMC5705535.

[120] A.D. McEachran, J.R. Sobus, A.J. Williams, Identifying known unknowns using the US EPA's CompTox chemistry dashboard, Anal. Bioanal. Chem. 409 (7) (2017) 1729-1735 Epub 2016/12/18. doi: 10.1007/s00216-016-0139-z. PubMed PMID: 27987027.

[121] A.D. McEachran, K. Mansouri, C. Grulke, E.L. Schymanski, C. Ruttkies, A.J. Williams, MS-Ready" structures for non-targeted high-resolution mass spectrometry screening studies, J. Cheminform. 10 (1) (2018) 45 Epub 2018/09/01. doi: 10.1186/s13321-018-0299-2. PubMed PMID: 30167882; PMCID: PMC6117229.

[122] J.R. Sobus, J.N. Grossman, A. Chao, R. Singh, A.J. Williams, C.M. Grulke, A.M. Richard, S.R. Newton, A.D. McEachran, E.M. Ulrich, Using prepared mixtures of ToxCast chemicals to evaluate non-targeted analysis (NTA) method perfor mance, Anal. Bioanal. Chem. 411 (4) (2019) 835-851 Epub 2019/01/07. doi: 10.1007/s00216-018-1526-4. PubMed PMID: 30612177; PMCID: PMC6469933.

[123] N.G. Mahieu, G.J. Patti, Systems-level annotation of a metabolomics data set reduces 25000 features to fewer than 1000 unique metabolites, Anal. Chem. 89 (19) (2017) 10397-10406 Epub 2017/09/16. doi: 10.1021/acs.analchem.7b02380. 
PubMed PMID: 28914531; PMCID: PMC6427824.

[124] Y. Djoumbou-Feunang, J. Fiamoncini, A. Gil-de-la-Fuente, R. Greiner, C. Manach, D.S. Wishart, BioTransformer: a comprehensive computational tool for small molecule metabolism prediction and metabolite identification, J. Cheminform. 11 (1) (2019) 2 Epub 2019/01/07. doi: 10.1186/s13321-018-0324-5. PubMed PMID: 30612223.

[125] I. Blazenovic, T. Kind, H. Torbasinovic, S. Obrenovic, S.S. Mehta, H. Tsugawa T. Wermuth, N. Schauer, M. Jahn, R. Biedendieck, D. Jahn, O. Fiehn, Comprehensive comparison of in silico MS/MS fragmentation tools of the CASMI contest: database boosting is needed to achieve 93\% accuracy, J. Cheminform. 9 (1) (2017) 32 Epub 2017/11/01. doi: 10.1186/s13321-017-0219-x. PubMed PMID: 29086039; PMCID: PMC5445034.

[126] E.L. Schymanski, C. Ruttkies, M. Krauss, C. Brouard, T. Kind, K. Duhrkop, F. Allen, A. Vaniya, D. Verdegem, S. Bocker, J. Rousu, H. Shen, H. Tsugawa, T. Sajed, O. Fiehn, B. Ghesquiere, S. Neumann, Critical assessment of small molecule identification 2016: automated methods, J. Cheminform. 9 (1) (2017) 22 Epub 2017/11/01, doi: 10.1186/s13321-017-0207-1. PubMed PMID: 29086042; PMCID: PMC5368104.
[127] R.C. Fry, P. Navasumrit, C. Valiathan, J.P. Svensson, B.J. Hogan, M. Luo S. Bhattacharya, K. Kandjanapa, S. Soontararuks, S. Nookabkaew, C. Mahidol, M. Ruchirawat, L.D. Samson, Activation of inflammation/NF-kappaB signaling in infants born to arsenic-exposed mothers, PLoS Genet. 3 (11) (2007) e207 Epub 2007/11/28. doi: 10.1371/journal.pgen.0030207. PubMed PMID: 18039032 ; PMCID: PMC2082467.

[128] R. Miura, A. Araki, C. Miyashita, S. Kobayashi, S. Kobayashi, S.-L. Wang, C.H. Chen, K. Miyake, M. Ishizuka, Y. Iwasaki, An epigenome-wide study of cord blood DNA methylations in relation to prenatal perfluoroalkyl substance exposure: the Hokkaido study, Environ. Int. 115 (2018) 21-28.

[129] J.E. Rager, R.C. Fry, Systems biology and environmental exposures, in: W. Zhang (Ed.), Network Biology, Nova Science Publishers, 2013, pp. 81-130.

[130] R.C. Fry, C. Carberry, J.E. Rager, Use of genome editing tools in environmental health research, Curr. Opin. Toxicol. (2019).

[131] S. Tuovinen, J.G. Eriksson, E. Kajantie, K. Raikkonen, Maternal hypertensive pregnancy disorders and cognitive functioning of the offspring: a systematic review, J. Am. Soc. Hypertens. 8 (11) (2014) 832-847 e1. Epub 2014/12/03. doi: 10.1016/j.jash.2014.09.005. PubMed PMID: 25455009. 